\title{
Evaluasi Cambridge International Primary Program Siswa SD Al-Azhar pada Mata Pelajaran 'English Language'
}

\author{
Ria Herwandar, Denny Azhari Safryono \\ Program Studi Sastra Inggris, Fakultas Sastra \\ Universitas Al Azhar Indonesia, Jl. Sisingamangaraja, Jakarta 12110 \\ Penulis untuk korespondensi/E-mail: ria_herwandars@uai.ac.id
}

\begin{abstract}
Abstrak - Analisis materi ujian bahasa Inggris Cambridge Primary Checkpoint merupakan bagian dari penelitian Evaluasi Cambridge International Primary Program siswa SD Al-Azhar pada mata pelajaran "English Language. Peneliti ingin membuktikan bahwa teori pemerolehan bahasa ke dua pada anak usia dini dapat dibuktikan melalui hasil capaian ujian yang dikelola oleh Cambridge. Terbukti bahwa anak (usia 12-130) mampu menguasai bahasa ke dua dengan baik apabila dilaksanakan dengan benar.
\end{abstract}

Abstract - The analysis of English Examination of Cambridge Primary Checkpoint has been a part of the research with the title "Evaluation of Cambridge International Primary Program of elementary students of Al-Azhar on 'English language"'. The researcher wishes to identify that the theory of second language aquisation on children has been proved adequately through the analyses of examination results which has been conducted in Al-Azhar primary school. It is identified that children (age 12-13) are capable of mstering other language when it is given in the proper manner.

Keywords - Cambridge Primary Checkpoint, reading, writing, usage and evaluation

\section{PENDAHULUAN}

$\mathrm{E}$ ra globalisasi ditandai dengan persaingan ketat di semua bidang seperti teknologi, management dan sumber daya manusia (SDM). Bidang pendidikan bahasa Inggris mendapat prioritas utama untuk dikuasai dan diajarkan bukan saja di tingkat SMA dan SMP tetapi juga di tingkat SD dan bahkan di tingkat Taman kanak-kanak. Bahasa Inggris menjadi keharusan apabila ingin meningkatkan kualitas pendidikan untuk bersaing di lingkup dunia. Maka timbullah kelas kelas bilingual di semua jenjang pendidikan jauh sebelum dikeluarkannya Undang-undang Republik Indonesia No 20 tahun 2003 tentang Sistim Pendidikan Nasional sebagai dasar hukum penyelenggaraan dan reformasi sistim pendidikan nasional, dimana pada pasal 50 ayat 3 menyatakan bahwa "Pemerintah dan/atau Pemerintah Daerah menyelenggarakan sekurang-kurangnya satu satuan pendidikan pada semua jenjang pendidikan untuk dikembangkan menjadi satuan pendidikan yang Bertaraf Internasional"[1].

Kelas bilingual tingkat SD, SMP dan SMA merupakan langkah persiapan untuk menuju RSBI, dan sesuai dengan visi dan misi pendidikan nasional yang menekankan bahwa pendidikan nasional harus mampu mengembangkan manusia Indonesia yang berkualitas sehingga mampu dan proaktif menjawab tantangan zaman yang selalu berubah dengan cepat. Pendidikan diharapkan mampu menciptakan manusia yang siap bersaing di tingkat regional, nasional dan internasional. Walaupun Undang-undang Republik Indonesia No 20 tahun 2003 tentang Sistim Pendidikan Nasional yang menerapkan penyelenggaraan satuan pendidikan bertaraf Internasional dihapuskan, banyak sekolah yang tetap meneruskan pelaksanaan RSBI ini secara mandiri karena dianggap sangat dibutuhkan untuk mempersiapkan anak didik agar mampu bersaing didunia kerja.

Ketika Program Rintisan SMA Bertaraf Internasional diterapkan di SMA Al Azhar dengan melibatkan pola pendidikan Cambridge International Examination, para pimpinan Yayasan Pendidikan Al Azhar akhirnya menetapkan pula bahwa kurikulum Cambridge harus diawali mulai dari jenjang pendidikan yang paling bawah yaitu di tingkat SD agar menjadi satu kesatuan 
pendidikan yang lengkap dan berkesinambungan sampai SMA.

Dengan pemikiran diatas, maka Pimpinan Yayasan Pendidikan al Azhar, mendaulatkan pimpinaan Cambridge International Examination di Al Azhar menyelanggarakan bukan saja program ujian Cambridge untuk tingkat SMA yang dinamakan IGCSE, tetapi juga membuka ujian Cambridge ditingkat SD dengan menerapkan Primary Cambridge Education. Walaupun kurikulum local tidak diubah, namun dengan dimasuknya komponen silabus dan kurikulum Cambridge ke dalam kurikulum local maka perubahan yang terjadi di tingkat SD sampai dengan SMA tentu menjadi suatu pekerjaan yang cukup besar yang harus dikerjakan oleh sekolah sekolah Al Azhar di Jakarta.

Ketika kurikulum Cambridge diterapkan pada tingkat SMA, para pendidik tentu optimis mengingat siswa SMA telah memiliki jam kerja pembelajaran bahasa Inggris bertahun tahun sehingga hanya dengan kerja keras di pihak guru dan siswa, maka keberhasilan tampak menjadi sangat jelas. Permasalahannya adalah bagaimana program Cambridge Primary akan berhasil dilaksanakan karena siswa SD adalah siswa yang baru berumur 6 tahun sampai dengan 12 tahun. Kondisi biologis, otak dan kognitif bahasa mereka masih tumbuh kembang. Proses apakah yang terjadi di kepala mereka terkait dengan pemerolehan bahasa pertama dan kedua. Dapatkah mereka memiliki kemampuan yang diharapkan sesuai benchmark Cambridge Primary sementara kemampuan bahasa Indonesia sebagai bahasa pertama juga masih dalam proses pencapaian yang belum sempurna. Bagaimana capaian keberhasilan ketika mereka mengerjakan ujian Cambridge Primary. Kemahiran apa saja yang tercermin dalam kurikulum Cambridge Primary. Masalah lain yang penting dipecahkan adalah apakah pembelajaran bahasa ke dua bagi anak yang belum dewasa akan memberi input yang lebih baik pada proses pembelajaran secara utuh di segala bidang di masa dewasa mereka.

Masalah ini dapat terungkap melalui penelitian data data yang akan dikumpulkan baik data kepustakaan sebagai kajian teori pemerolehan bahasa pertama dan kedua pada anak dan pengetahuan psikolinguistik pemerolehan bahasa pada anak dan Second language Acquisition, berkaitan dengan assessment pemerolehan bahasa ke dua. Peneliti mencari data tidak sebatas data teori tetapi juga menganalisis kurikulum dan silabus Cambridge Primary, materi ujian dan data hasil ujian Cambridge Primary Examination siswa Al-Azhar dalam dua atau tiga periode.

\section{Perumusan Masalah}

1. Kurikulum dan silabus apa yang ada dalam dalam pembelajaran bahasa Inggris Cambridge.

2. Materi apa yang ada dalam ujian bahasa Inggris Cambridge

3. Bagaimana hasil ujian Cambridge sebagai capaian pembelajaran bahasa Inggris pada murid sekolah dasar Al Azhar.

\section{Tujuan Penelitian}

Tujuan umum dari penelitian ini adalah melihat kemahiran dan pemerolehan bahasa kedua (bahasa Inggris) pada anak sampai usia 13 tahun. Dengan demikian, penelitian ini mengkhususkan pengamatan pada kegiatan seperti:

1. Mendeskripsikan Kurikulum dan silabus apa yang ada dalam dalam pembelajaran bahasa Inggris.

2. Menjelaskan materi apa yang ada dalam ujian bahasa Inggris Cambridge.

3. Menganalisis hasil ujian Cambridge sebagai capaian pembelajaran bahasa Inggris pada Murid sekolah dasar Al Azhar.

\section{Manfaat Penelitian}

Manfaat yang akan didapat dari penelitian ini adalah pemahaman bahwa belajar bahasa lain (second language) selain bahasa ibu (first language) pada anak usia sekolah dasar bisa dilaksanakan. Peneliti akan menjelaskan capaian yang telah diperoleh para pembelajar sekolah dasar Al Azhar dalam melaksanakan ujian Cambridge dan memaparkan tingkat kesulitan materi ujian bahasa Inggris yang pada kurikulum pendidikan dasar bahasa Inggris. Penelitian ini dapat memberi pencerahan bagi para pengajar untuk bagaimana mengajarkan bahasa kepada anak dengan baik dan benar.

\section{KAJIAN TEORI}

\section{Pemerolehan Bahasa Pertama dan Kedua pada anak}

Metode Penelitian ini merupakan penelitian Kualitatif deskriptif dengan menggunakan teori Pemerolehan bahasa pertama dan kedua pada anak. Soeyono mengatakan bahwa sejarah kajian pemerolehan bahasa sudah dilakukan oleh raja Mesir [2].Raja memerintah bawahannya meneliti 
perkembangan bahasa dua anak pada abad 7 sebelum Masehi dan berkembang sampai masa kini melalui beberapa metode penelitian diantaranya melalui studi Longitudinal dan Crosssectional.

Dengan munculnya buku Chomsky Syntsctic Structures, tumbuhlah aliran mentalisme atau nativisme pada ilmu linguistik yang menegaskan bahwa anak sejak lahir membawa kodrati dimana anak dimanapun akan memakai strategi yang sama dalam memperoleh bahasanya [2].

\section{Universal Bahasa}

Menurut Seoyono, karena anak mampu memperoleh bahasa apa pun yang disajikan kepadanya, tentu ada sesuatu yang sifatnya universal pada bahasa bahasa yang ada didunia [2]. Greenberg meneliti berbagai bahasa dan menemukan persamaan dan perbedaan dalam bahasa Bahasa [3]. Comrie dalam Seoyono membedakan universal bahasa menjadi absolute dan tendensius [2]. Misalnya yang dimaksud dengan universal absolute adalah semua bahasa memiliki vocal /a/, /i/, dan /u/. Sementara Chomsky membedakan universal menjadi dua bagian, yaitu universal substantif dan universal formal. Contoh untuk universal substantif adalah unsur atau elemen yang membentuk bahasa seperti nomina, verba dan ajektiva. Elemen ini ada dalam hampir semua bahasa. Universal formal mengatur bagaimana universalsubstantif di kelola. Penanganan elemen element ini berbeda dari satu bahasa ke bahasa yang lain. Dengan demikian walaupunpada intinya bahasa itu sama, namun bentuk lahiriahnya berbeda beda.

Menurut Chomsky dalam Seoyono, manusia memiliki faculty of the mind dalam otaknya,yaitu kapling kapling intelektual dan salah satunya untuk bahasa. Oleh Chomsky, kapling kodrati ini diperoleh sejak lahir dan diberi nama Language Acquisition Device, LAD atau terjemahannya menjadi Piranti Pemerolehan Bahasa PPB [4]. Ketika berbicara maupun mendengar PPB menjaring semua ujaran dan melalui mekanimsme untuk memilah dan menjaring sehingga yang di ambil hanya yang terbaik atau terapik. PPB dapat disebut sebagai pembuat hipotese dan menyarikan korpus yang masuk.

Chomsky menggambarkan pemerolehan bahasa seperti orchestra yang memainkan sebuah simfoni. Dari bunyi satuan satuan yang sederhana saling mengisi menciptakan nada yang indah dan kompleks. Gambaran inilah yang dimaksud dengan Pemerolehan bahasa. Orkestra itu diibaratkan sebagai tata bahasa Universal atau TU, terdiri dari beragam alat alat dalam orchestra, atau dalam Tata bahasa Universalnya disebut modul dengan prinsipelnya sehingga ada aturan main kapan digunakannya. Demikianlah ringkasan pemerolehan bahasa yang sudah ada dalam benak anak manusia. Dalam kapling kodrati yang dibawa sejak lahir terjadi proses hubungan antara linguistik universal diterima oleh Piranti Pemerolehan Bahasa kemudian dipilah dan disaring melalui pembuat hipotese sehingga mampu mengevaluasi orchestra yang dinamakan tata bahasa atau gramatika sesuai berdasarkan modul modul dan dan primsipelnya. Proses pemahaman dan pemakaian gramatika dalam suatu bahasa ini akan seindah simfoni yang dimainkan oleh orchestra itu.

\section{Periode Kritis Pemerolehan bahasa}

Perkembangan biologis anak sangat mempengaruhi pemerolehan bahasa. Sebelum anak mampu mengucapkan huruf ' $r$ ' misalnya, dia harus melalui pengucapan sederhana seperti 'papa', 'mama'. Oleh karena itu, Brown mengatakan Hipotesis Periode Kritis atau CPH (the critical Period Hypothesis) telah diteliti pakar psikolinguistik yang mengatakan bahwa ada periode kritis dalam usia manusia bagi pemerolehan bahasa., dimana bahasa bisa dikuasai dengan mudah pada masa atau usia kritis ini [5]. Peneliti Lenneberg dan Bickerton percaya bahwa kemampuan kemampuan tertentu tidak mungkin berkembang sebelum dan sesudah rentang waktu tersebut [5]. Awalnya periode kritis hanya dikaitkan dengan pemerolehan bahasa pertama, namun pada tahun tahun terakhir banyak peneliti seperti Loup Singleton \& Ryan menerapkan $\mathrm{CPH}$ pada pemerolehan bahasa kedua. Para peneliti berargumen bahwa $\mathrm{CPH}$ terjadi pada sekitar usia akil balik atau 12 -13 tahun [5]. Menurut Brown, beberapa peneliti melihat anak 2 yang belajar bahasa kedua menggunakan sebuah proses konstruksi kreatif seperti yang anak anak itu lakukan dalam bahasa pertama mereka [5].

\section{Kurikulum Pendidikan Dasar Cambridge}

Faktor penting lainnya yang akan dianalisis adalah Curriculum Framework of Primary English. Kerangka kurikulum ini berlandaskan gabungan antara kurikulum nasional Inggris dan kurikulum Internasional sesuai dengan karakter pengguna kurikulum Cambridge yang terdiri dari siswa di seluruh dunia. Kerangka kurikulum The 
Cambridge Primary English di bagi menjadi 6 tahapan ( kelas 1-6) dengan kisaran umur mulai 5 tahun pada stage 1 sampai umur 11 tahun pada stage 6 . Ujian dilaksanakan pada tingkat akhir di kelas 6. Perkembangan bahasa baru di ujikan di kelas 3, 4, 5 dan 6. Agar guru dapat memonitor perkembangan siswa. Ujian yang berbentuk progess test bukan untuk menaikkan atau menggugurkan siswa tetapi cukup berupa paparan perkembangan pembelajaran. Kerangka kurikulum yang memaparkan tingkat kesulitan berjenjang, di bagi menjadi 4 kelompok untuk setiap tingkat kelas mulai dari kelas 1 sampai dengan kelas 6 yakni:

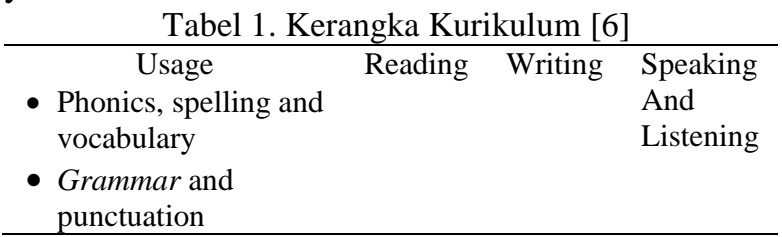

Berikut ini adalah gambaran gradasi kurikulum mulai dari kelas 1sampai dengan kelas 6 pada setiap kelompok [6].

\section{Kelompok USAGE (Phonic, spelling and vocabulary) and (Grammar and punctuation) \\ Kelas 1}

(phonic, spelling and vocabulary) Murid harus mampu:

1. Mendengar, membaca dan menulis bunyo huruf awal

2. Mengetahui nama yang bunyinya umumterkait dengan huruf bahasa Inggris

3. Membedakan bunyi 9phonemes) dalam kata yg dilambangkan dengan huruf lebih dari satu seperti 'th', 'ch', 'sh'

4. Menggunakan bunyi huruf yang diketahui untuk membaca dan menulis kata 2 bersilabel satu yg memiliki huruf hidup yang pendek

5. Menggabungkan antara membaca dengan mengeja, kata kata yang berakhiran atau diawali dengan berkonsonan seperti $b-l, n-d$

6. Mulai belajar ejaan umum dengan huruf hidup yang panjang seperti ' $e e$ ', ' $a i$ ', 'oo'

7. Menggunakan bunyi yang sudah diketahui untuk menulis kata kata umum dan berkreasi menulis kata lain

8. Mengeja kata kata yang diketahui dengan tepat, menggambar kosakata yang terlihat disekeliling

9. Gunakan rima dan hubungkan pola pengejaan

10. Kenali kata kata umum yang berakhiran dengan denga - s, sed, -ing

(Grammar and punctuation) Murid harus mampu"
1. Berhenti pada tanda titik ketika membaca

2. Mengenal kalimat dalam teks

3. Mengetahui fungsi huruf besar untuk $I$, untuk proper noun dan apabila memulai kalimat.

4. Menulis titik pada kalimat. Menulis kalimat dengan menggunakan and

\section{Kelas2}

(phonic, spelling and vocabulary) Murid harus mampu:

1. Belajar membedakan ejaan umum dari huruf hidup yang panjang

2. Belajar ragam pengucapan huruf hidup seperti'how, low, apple, apron

3. Belajar menerapkan pengetahuan fonem dan pola pelafalan dalam tulisan secara mandiri

4. Perdalam pengejaan kata kata yang sering dipakai dan kata kata yang ujarannya tidak beraturan

5. Mengidentifkasi silabel dan memisahkan kata kata kedalam bagiannya

6. Ujarkan kata kata dengan prefix yang umum seperti: un-,dis-, -ful, -ly

7. Buat dan praktekkan kata kata yang menarik

8. Diskusikan arti kata kata yang baru yang ditemukan dalam bacaan

9. Pilih kata kata yang menarik atau frasa misalnya untuk menjelaskan ciri ciri seseorang dan tempat

(Grammar and punctuation) Murid harus mampu:

1. Mulai membaca dengan lancar dan berekspresi, menempatkan punktuasi, dan cirri ujaran

2. Baca dan merespon terhadap pertanyaan seperti :where, what, when, who, why

3. Membuat kaliamt yang jelas dengan menggunakan huruf besar diawal kata, titik dan pertanyaan.

4. Gunakan past dan present tense dengan tepat walau tidak konsisten

5. Menulis kalimat kalimat sederhana dan kalimat berjenjang dengan menggunakan ans/ but untuk menghubungkan gagasan. Kalimat kompleks bisa menggunakan kata hubung because

6. Membuat variasi kalimat pembuka dengan adverbia yang sederhana.

7. Mampu menggunakan headings dan captios

8. Membaca ulang tulisan sendiri untuk melihat makna dan ketepatan.

\section{Kelas 3}

(phonic, spelling and vocabulary) Murid harus mampu:

1. Memiliki strategi yang efektif menghadapi kata kata baru ketika membaca, cara 
membacanya, memisahkan kata tersebutdalam silabel, menggunakan analogi, melihat sufiks dan prefix dalam konteks

2. Menggunakan dan mengeja compound worda

3. Mengerti yang mana irregular verbs dari kata kerja

4. Mempelajari pola penggunaan -ing,-ed, -s pada verba

5. Mengembangkan prefix dan suffuiks yang sebelumnya sudaqh dipelajari

6. Menggali kata kata yang pengejaannya sama tetapi beda makna seperti form, wave

7. Menggunakan kamus dan alat elektronik lain untuk mendapatkan arti kata dan cara mengucapkannya

8. Menggorganisasikan kata kata secara alfabetik

9. Mengidentifikasi katakata yang salah menulisnya dan membiasakan memeikik buku cara mengeja

10. Melihat bahwa pilihan kata yang tepat akan memperkuat makna

11. Menginferensi makna dari konteks

12. Mengeksplorasi kosa kata untuk pembuka dan penutup percakapan seperti:said, asked

13. Mampu mencari sinonim dari kata kata yang sering muncul seperti: big, little, good

(Grammar and punctuation) Murid harus mampu:

1. Dengan pengetahuan tanda baca dan tata bahasa didimilik, siswa mampu membaca dengan lancar, memahamidanmenggunakanekspresi yang tepat

2. Memahamipenggunaan kutipan sampai koma untuk memendekan kata seperti: can't, don't

3. Menyeleksi contoh kata nomina,verba dan ajektiva, dean menggunakannya dengan benar

4. Mengidentifikasi pronominal dan mengerti fungsinya dalam kalimat

5. Mengetahui pentingnya verba dalam kalimat

6. Mengerti pluralisasi dan menggunakan terminology tunggal dan jamak

7. Menggunakan huruf besar, dan tanda baca yang benar dalam penulisan

8. Menggunakan tenses yang benar dankonsisten

9. Pastikan penggunaan yang bersetuju antara pronominal dan verba

10. Menggunakan variasi kalimat mulai yang sederhana berjenjang dan kompleks

11. Menggunakan adverbial sebagai pembuka kaliamat.

\section{Kelas 4}

(phonic, spelling and vocabulary) Murid harus mampu:

1. Memperluas pengetahuan polafonem huruf hidup, dua konsonan, huruf mati, prefiks dan sufiks umum

2. Mengetahui pola to be dan kapan saja dipakainya

3. Mengaplikasikan ejaan, grafik, tata bahasa, konteks ketika memaknai kata kata sulit

4. Identifikasi silabel dalam kata kata yang panjang

5. Menglafal kata kata yang mirip seperti; tough, through, trough, plough

6. Mencocokan penglafaalan yang sama dengan makna yang berbeda 9homophones) seperti: to/ two/ too/, right, write

7. Use more powerful verbs, seperti: rushed instead of went

8. Mengeksplorasi tingkatintensitas dalam ajektiva, seperti:cool, tepid, warm, hot

9. Mencari kata lain untuk kata kata atau ekspresi yang sering dipakai

10. Memilih dan mengklasifikasikan katakata kedalam akar kata yang umumseperti,invent prevent

11. Membangun kata dari kata lain dengan makna yang mirip seperti; medical, medicine

(Grammar and punctuation) Murid harus mampu:

1. Menggunakan pengetahuan tanda baca dan tata bahasa dalam membaca dengan lancar, paham dan berekspresi

2. Mengidentifikasi tanda baca dan mempraktekkan

3. Mengerti pemakaian apostrofi kepemilikian contoh girl's, girls'

4. Menggunakan komadalam kalimat

5. Mengidentifikasi adverbial dan dampak pada maknanya

6. Mengidentifikasi pat, present, dan future tenses of verbs

7. Menginvestigasi gramatika di kalimst yang berbeda beda:statement, questions and order

8. Mengerti ketika menggunakan konektif pada struktur argumentasi seperrti: if , although

\section{Kelas 5}

(phonic, spelling and vocabulary) Murid harus mampu:menerapkan kemahiran membaca, gramatika dan tanda baca pasa level 5 . 


\section{Kelas 6}

(phonic, spelling and vocabulary) Murid harus mampu:menerapkan kemahiran membaca, grammar dan tanda baca pada level 6.

\section{Grammar and Punctuation (Writing)}

Begin to use the comma to separate clauses within sentences and clarify meaning in complex sentences

Use an increasing range of subordinating connectives

Practise proofreading and editing own writing for clarity and correctness

\section{Grammar and Punctuation (Fiction and Poetry) \\ Read widely and explore the features of different fiction genres \\ Discuss metaphorical expressions and figure of speech \\ Identify the point from which the story is told}

Kerangka kurikulum ini akan terlihat dalam materi ujian yang akan dianalisis rincian yang diujikan pada anak Sekolah Dasar al Azhar.

\section{METODE PENELITIAN}

\section{Pendekatan Penelitian}

Penelitian ini menggunakan pendekatan kualitatif deskriptif berdasarkan penelitian evaluatif, studi kasus siswa sekolah dasar Al azhar yang bersifat deskriptif melalui kegiatan studi kepustakaan, penelitian lapangan dan hasil analisis ujian akhir Cambridge Primary Check Point.

\section{Partisipan Penelitian}

Partisipan penelitian adalah anak anak SD Al Azhar kelas 5 dan 6 tahun 2012 dan 2013, yang mendaftarkan diri mereka untuk mengikuti ujian. Peserta ujian tahun 2012 hanya 27 peserta sedangkan peserta ujian tahun 2013 jumlahnya mencapai 61 siswa. Pada dasarnya mereka telah belajar bahasa Inggris baik di kelas bilingual di alAzhar maupun di tempat kursus di luar sekolah. Mereka juga mendapat masukkan soal materi pembelajaran Cambridge sebelum ujian sehingga mereka telah dibekali pola pola pembelajaran Cambridge.

\section{Waktu dan Tempat}

Peserta ujian, walaupun telah menguasai bahasa Inggris dengan baik, hanya mendapat bimbingan melakukan latihan materi ujian Cambridge dalam waktu singkat karena keterbatasan waktu persiapan. Ujian Cambridge Primary Checkpoint dilaksanakan di gedung sekolah SD Al Azhar. Ujian bahasa Inggris berlangsung selama dua jam. Jam pertama untuk ujian Paper 1 dan jam kedua untuk Paper 2.

\section{Metode Analisis Data}

Data yang akan dirujuk adalah analisis materi ujian siswa 2012. Materi ini terdiri dari dua bagian yakni paper 1 dan paper 2. Penilaian ujian ini bersadarkan kriteria kemampuan bahasa secara umum, kemampuan membaca dan komprehensi, pemakaian bahasa atau usage dan penulisan. Peneliti awal akan menganalisis materi ujian dan capaian anak 2012. Berapa yang terbaik, berapa yang cukup dan berapa yang lemah. Setelah itu siswa yang mengikuti ujian tahun 2013 akan menjadi pembanding. Apakah ada peningkatan hasil ujian atau tidak. Diharapkan ada kemajuan signifikan mengingat para siswa 2013 memiliki waktu yang lebih lama dalam mempersiapkan ujian Cambridge Primary Checkpoint. Hasil akhir akan memperlihatkan capaian nilai 4 komponen yang diujikan yakni English, Reading, Usage dan Writing.

\section{HASIL DAN PEMBAHASAN}

\section{Analisis Materi Ujian Bahasa Inggris Cambridge Primary Checkpoint 2012}

Pada ujian 2012 materi dibagi menjadi paper 1 dan paper 2.Paper 1 berlangsung 1 jam dan terdiri dari Bagian A dan B. Bagian a diawali dengan teks sederhana berjudul When the Titanic Hit an Iceberg dan diberi padanan kata kata sulitnya atau glossary.Dari teks tersebut siswa harus menjawab beragam jenis pertanyaan yang merujuk pada kemahiran komrehensi pada pertanyaan 1,2 , dan 3. Pertanyaan 4, siswa harus membuat ringkasan sebanyak 30 kata dari kejadian inti yang terjadi dalam teks. Pertanyaan 5 siswa diuji untuk menentukan apakah informasi dalam treks bernuansa fakta atau opini. Pertanyaan 6 menguji siswa untuk mengenali topik yang sama dalam 2 tipe teks berbeda dan memberikan pilihan teks yang mereka sukai dan apa alasannya. Disini siswa harus menentukan ciri ciri masing masing teks apakah formal atau tidak. Pertanyaan no 7,8 dan 9 merujuk pada teks ke dua berjudul Big Blue whale yang memiliki sub judul 1. How big, 2 General features dan 3. Breathing dengan konsentrasi pada pertanyaan komprehensi. Pertanyaan no 10 merujuk pada perbandingan antara peran sub judul dengan paragraf yang ada di 
teks pertama. Pada Bagian B paper 1 siswa harus mengarang dengan topik Human beings dengan format laporan seperti judul Big Blue Whales.

Paper 2. Berlangsung 1 jam. Teks panjang diberikan terpisah dari lembar pertanyaan bersumber dari sebuah novel berjudul Stig of the Dump by Clive King. Paper 2 cenderung lebih sulit dibandingkan dengan paper 1. Bagian A, pertanyaan no1 menjawab 4 butir apa yang benar dalam teks. Pertanyaan no 2 merinci hal yang dilihat tokoh dalam suatu kejadian. Pertanyaan 3,4, 5 dan 6 memberi alasan dan penyebab sehingga siswa harus menulis kalimat panjang dan kompleks untuk memaparkan penjelasan mereka. Pertanyaan no 7 menuntut siswa untuk memberikan penjelasan panjang berikut bukti berupa kata kata, frasa sebagai penunjang penjelasan mereka.Pertanyaan 8 dan 9 merujuk pada pertanyaan komprehensi sementara pertanyaan no 10 membahas alasan mengapa tokoh cerita dianggap sebagai the point of view character dan berikan 2 alasan. Pertanyaan no 11 mengenali jenis kalimat apakah kalimat pendek, panjang atau paragraf pendek atau fragmen kalimat. Pertanyaan 12 mengidentifikasi jenis cerita novel itu apakah termasuk dalam adventure story, biography, legend, science fictionatau traditional tale. Lebih jauh siswa ditanya mengenai 2 fiture yang ada dalam genre jenis teks yang dipilih.

Bagian B adalah penulisan atau writing. Pertanyaan no 13 diawali dengan ringkasan cerita yang diikuti dengan kalimat There was somebody there ! or something! . Siswa diminta untuk meneruskan mengarang cerita dengan panduan gagasan dalam merinci karakter, situasi dan plot cerita. Siswa harus mampu menceritakan rincian penting dan bebas memilih genre tulisan mereka. Sebelum mengarang siswa harus mengisi kolom planning terlebih dahulu..

\section{Paparan Analisis Hasil Ujian Siswa 2012}

Secara umum ke 27 siswa Sekolah dasar Al Azhar mampu melaksanakan ujian dengan baik. Setelah dianalisis, seluruh peserta, apabila diukur tingkat kemahiran bahasa Inggris melalui penilaian dari sudut pandang (1) kemahiran bahasa Inggris secara keseluruhan, (2) membaca/ Reading, (3) pilihan bahasa/ Usage dan (4) Menulis/ Writing, dapat dibagi menjadi 3 kelompok yakni kelompok baik berjumlah 10 siswa dengan rata rata nilai 3,5-4, kelompok bernilai cukup cukup 10 siswa dengan nilai rata rata 3-34 dan yang mendapat penilaian kurang sebesar 7 siswa dengan nilai ratra rata 2- 3 . Dibawah ini akan diperlihatkan contoh karya tulis siswa di tiga tingkat kemahiran yang tercermin dalam paper 1 dan paper 2 .

Contoh tingkat kemahiran kurang atau terendah dalam Paper 1.dengan judul Human Beings

\section{Contoh Siswa A dengan tingkat kemampuan rendah atau kurang}

"Humans live on earth. Humans eats vegetables, fruits and meats. Humans can talk, swimming, jumping, making a thins, running, playing and etc. Usually humans sleep at night and get up in the morning. Humans must to eat to grow well. Humans breathes air. Humans had two eyes, 2 ears,I mouth, 2 arms , 2legs 1 head and 1 body."

Analisisnya adalah karangan siswa A termasuk terpendek dan memiliki banayak kesalahan yang jelas dipengaruhi latar bahasa Indonesianya. Dalam penulisan bahasa Indonesia, kata jamak dan tunggal hanya terlihat melalui numeria. Dalam bahasa inggris harus menggunakan kamlimat majemuk atau singular. Humans adalah jamak tetapi kata kerja yang digunakan adalah tunggal menggunakan s. siswa juga tidak bisa membedakan kata yg dapat dihitung atau tidak dapat dihitung. Meat is uncountable tapi diberi s. Pengaruh bahasa Indonesia lainnya pada siswa ini adalah pemahaman mengenai kala atau tenses. Dalam bahasa Indonesia dalam mencerminkan kala cukup menggunakan kata sekarang, besok atau kemarin. Sementara dalam bahasa Inggris memiliki banyak ekspressi manakala ingin mengungkapkan kala atau tenses. "Human had two eyes" seharusnya "has two eyes". Kata must to grow juga kesalahan yg mencerminkan kompleksitas verba must sebagai verba khusus dengan pola yang khusus pula dimana setelah must langsung diikuti oleh verba tanpa infinitive dan setelah can tidak dapat diikuti dengan gerund (ing). Disini tercermin interferensi bahasa indonesia siswa yang cukup jelas namun karena bahasa memiliki persamaan dalam perbedaannya, pembaca masih mengerti isi keseluruhan ungkapan siswa ini.

\section{Contoh siswa B dengan tingkat kemahiran cukup}

"All of human beings are smart. They eat twice a day. They eat meat and vegetable. They can run, walk and etc. they live in a house with their families. 
Everyday, they are growing. They go to school everyday to study. Usually, they take a bath twice a day.

When they were born, their called baby, then children then adultd. They all gonna be married someday and had a baby.

They sleep twice a day at noon and at midnight. When they took their bath, they brushed their teeth with toothpaste and toothbrush. All human beings are pretty and handsome."

Analisis karangan tersebut adalah penguasaan gramatika dan kala atau tenses jauh lebih baik bahkan sangat baik dibandingkan dengan siswa A. Pilihan kata tepat dan tenses yang digunakan beragam namun tepat siswa B menggunakan presnt tense, present continous, bahkan passive. Hanya ketika menggunakan kalimat conditional brushed tidak sepenuhnya benar. Dari seluruh teks hanya ada 2 kesalahan yakni yang benar seharusnya "they are called", dan "they brush". Ekspresi "They all gonna be married" yang digunakan jelas merupakan pemerolehan bahasa dari luar kelas, karena kalimat tidak formal ini tidak pernah diberikan dikelas. Kemungkinan siswa mendapatkannya ketika menonton film ber bahasaInggris atau membaca novel. Kesimpulan secara umum adalah siswa ini dengan umur yang masih muda 12 tahun atau lebih telah mengalami pembelajaran bahasa ke 2 dengan baik dan biasanya penguasaan bahasa pertamanya juga rapi danmembuka diri untuk menerima bahasa Inggris tidak hanya di kelas tetapi di luar kelas baik secara formal ataupun tidak formal. Peneliti meletakkan pada tingkat kemahiran cukup karena walau sudah trertip tetapi belum sepenuhnya mampu mengekspresikan diri dengan bebas.

\section{Contoh siswa $\mathrm{C}$ dengan tingkat kemahiran baik}

1. What is human beings

"Human beins is any race/ kind of homo sapiens. I means human included in human beings categor. History of human seperated into two source, the resources and religion. In resource, it says human ivolving from a monkey-like creature, But, based on religion, it says God create adam, the first human, and leave him in earth for punishment."

\section{How human birn}

"Human born from other human, or we called mother/woman. It stays in their mother's womb averagelly for 9 months. The process is really tiring, as everything pregnant woman do will affect their babies pyhisic and personality. The tiring process not end yet, even after the babies see the world. The mother will be very tired and the babyie has to be stabilized too."

\section{Needs of human}

Human needs food, water, education, and everything to survived in the world. When we are still a babies, we cry to make people know we are sick, needs food, needs milk and etc. when we grow up, we need education to find work. We need place ti live too. It needs to be fullfiilled unless you want to die."

Analisis karangan siswa $\mathrm{C}$ masih mencerminkan kesalahan secarsa grammatikal. Namun apabila dilihat dari cara mengekspresikan gagasannya, siswa $\mathrm{C}$ jauh lebih kreatif daripada siswa A dan B. Disamping kreatif siswa ini memiliki pikiran kritis sehingga informasi yang diberiukan sangat spesifik dan unik. Agar mampu mengekspresikan diri secar kritis, siswa $\mathrm{C}$ mampu menggunakan kosa kata yang baik, akademis dan frasa yang rumit. Pengaruh bahasa Ibu atau bahasa Indonesia tercermin ketika ia mengatakan leave him in earth karena dalam bahasa Indonesia terjemahannya hidup di bumi yang seharusnya leave him on earth. Berpikir kritis yang dimiliki siswa $\mathrm{C}$ ini bisa ia dapatkan dari membaca banyak buku buku atau nasihat dari orang tua misalnya bagaimana seorang ibu berproses secara rumit melahirkan sekaligus membersakan anaknya. Disini terdapat kombinasi yang saling mendukung antara penguasaan bahasa, berpikir kritis yang dibekali oleh bimbingaan apa yang ia baca maupun bimbingan informasi dari orang tua dan lingkungan sehingga siswa ini mamapu mengungkapkan pemikirannya dalam tulisan yang berbobot dalam bahasa Inggris sebagai bahasa ke dua.

\section{Contoh siswa D Paper 2 dengan Tingkat kemampuan Kurang}

Topik yag dipakai adalah melanjutkan karangan menggunakan tokoh Barney: "Then, a man help him to go out from the creepers. Then Barney asked him what is your name. and he said hisname is Dean. He live in the den. And Barney saij thank you to him because dean save his life.Dean asked him why si he here.Barney said he fall. Dean tell Berney the only way to go out from here is climbing. So dean helps him to climb the wall. And then, Barney can get out"

Analisis karangan siswa D adalah kalimat pendek yang tidak berkembang. Paragraf terlalu pendek sehingga cerita tidak dapat diketahui secara utuh. 


\section{Contoh siswa E Paper 2 dengan Tingkat kemampuan cukup}

"I've tried to got near him, and he was.....booommmmm he was a monster! The monster was angried to Barney because Barney was annoyed him. Barney tried to go, he almost cried!

The monsters wants to eat barney, but Barney runs very fast. The monster's name was Eglee. Then Eglee called his friends to get some help for catching Barney.Barney cried and he prayed to his God to get a help....30 menutes to go, there are a magic door, and Barney went to that place. Magically Barnry can go home."

Analisis karangan Siswa E adalah karangan ini dapat menghidupkan cerita dengan menggunakan kata kerja dinamis dan ajektiva yang mencerminkan kegiatan. Imaginasi dapat jelas terlihat walau pemilihan kata masih terbatas dan terdapat banayak kesalahan gramatikal.

\section{Contoh siswa F Paper 2 dengan Tingkat kemampuan baik}

"A strange-looking man appeared. He was holding a hot chocalate. Barney seemed pretty scared" Who are you?" said Barney. The man gave the hot chocolate. Barney then realized that this man is not dangerous. The man said" I am stiggy you could say that.

I am a caveman" then Barney nodded. Barney sipped the hot chocolate Stiggy gave him. "Why are you in here?" asked Stinggy. Barney replied " I fell from the old chalk pit" Barney walked around the den. Then he discovered that Stinggy has lived here for a long time. He walk to a door. He said "what is this?" Stinggy turned around. "I don't know but I can't open it,though" Barney saw a weird text in that door that says" Old Cherrychalk tree"

Analisis Teks $\mathrm{F}$ terdiri atas hampir 2 halaman yang tidak dimasukkansemua dalam penelitian ini. Cuplikan diatas sudah dapat menceritakan tingkat kemampuan siswa $\mathrm{F}$ dalam bercerita. Bahasanyabaik dan sesuai dengan penjabaran cerita. Gramatikanya tercermin rapi dan kosa kata sangat menunjang keberhasilan berceritanya. Kreativitas tercermin cerdas dan rapi.

\section{Analisis Komentar Siswa Secara Tertulis}

Komentar siswa SD alAzhar mengenai ujian tertulis mencerminkan posisis kemampuan mereka. Bagi mereka yang lemah mengatakan bahwa ujian bahasa Inggris Cambridge Primary
Checkpoint sulit. Bagi yang merasa mampu mengomentarinya sebagai ujian yang susah susah gampang. Sementara bagi yang berkeamampuan baik merasa sangat tertantang bahkan berkomentar "I love writing a story". Dari komentar mereka menandakan bahwa membekali mereka dengan bahasa kedua merupakan hal yang sangt positif karena mereka berusaha menguasai bukan saja bahasa tetapi juga kultur bahasa tersebut yang tentu sangat menarik untuk mereka pahami, kenali sebagai sesuatu yang magis sifatnya. Karena mengetahui bahwa ada suatu komunitas berbudaya lain selain di Indonesia. Apabila anak anak ditantang untuk mengekspresikan diri dalm budaya lain maka mereka akan menjadi lebih kreatif.

\section{Analisis Hasil Ujian Siswa 2013}

Ujian bahasa Inggris Cambridge Primary Checkpoint bahasa Inggris tahun 2013 dilaksanakan pada bulan Mei dengan hasil capaian yang berbeda dan lebih baik dari tahun sebelumnya. Dilihat dari jumlah peserta terlihat ada peningkatan yang signifikan yakni 61 peserta. Tahun 2012 hanya ada 30 siswa yang mengikuti ujian Cambridge Primary Checkpoint. Dari 61 siswa secara keseluruhan mendapatkan hasil rata rata sebagai berikut:

$\begin{array}{ll}\text { English (overall) } & \text { Nilai rata rata }=3.1 \\ \text { Reading } & \text { Nilai rata rata }=3.6 \\ \text { Usage } & \text { Nilai rata rata }=2.8 \\ \text { Writing } & \text { Nilai rata rata }=2.5\end{array}$

Penjelasan Skala Penilaian Cambridge Primary Checkpoint adalah

1. Nilai mulai dari angka 0 terendah dan angka 6 teringgi dari tingkat kemahiran

2. Siswa yang mendapat nilai angka 3.0 sampai 4.0 berarti telah mengerti dan menguasai isi kurikulum

3. Siswa yang mendapat nilai angka dibawah 2 berarti baru mencaapai tahap pengertian dasar dari isi kurikulum

4. Siswa yang mendapat nilai angka dari 5.0 berarti telah sangat menguasai isi kurikulum .

Penilaian selanjutnya adalah penilaian kemampuan individu kemahiran individu dari sub yang diujikan. Cambridge memberikan nilai prediksi performa dan apabila hasil ujian melebihi prediksinya maka pengajaran telah tercapai dengan benar. Apabila kemampuan individu kemahiran ada di tingkat yang tidak seperti di prediksikan 
maka dianggap pengajaran kemahiran tersebut lemah atau ketidak sempurnaan dalam pengajaran. Hasil Prediksi siswa SD Al-Azhar dari kemahiran subskill adalah sebagai berikut:

Tabel 2. Hasil prediksi subskill reading [6]

\begin{tabular}{ll}
\hline Reading & \\
\hline$R x$ & $\begin{array}{l}\text { Explicit Meaning } \\
\text { Performance was better than } \\
\text { expected }\end{array}$ \\
\hline$R i$ & $\begin{array}{l}\text { Implisit Meaning } \\
\text { Performance was better than } \\
\text { expected }\end{array}$ \\
\hline$R u$ & $\begin{array}{l}\text { Use of language } \\
\text { Performance was better than } \\
\text { expected }\end{array}$ \\
\end{tabular}

Tabel 3. Hasil prediksi subskill usage [6]

\begin{tabular}{ll}
\hline Usage & \\
\hline Up & $\begin{array}{l}\text { Punctuation } \\
\text { Performance was as expected }\end{array}$ \\
&
\end{tabular}

\begin{tabular}{ll}
\hline Un* & $\begin{array}{l}\text { Sentence structure } \\
\text { Performance was worse than } \\
\text { expected }\end{array}$ \\
\hline Us & $\begin{array}{l}\text { Spelling } \\
\text { Performance was as expected }\end{array}$
\end{tabular}

\begin{tabular}{ll}
\hline Uv & Vocabulary \\
& Performance was as expected
\end{tabular}

Tabel 4. Hasil prediksi subskill writing[6]

\begin{tabular}{ll}
\hline Writing & \\
\hline$W c$ & $\begin{array}{l}\text { content } \\
\text { Performance was as expected }\end{array}$ \\
\hline$W a^{*}$ & $\begin{array}{l}\text { Purpose and audience } \\
\text { Performance was worst than } \\
\text { expected }\end{array}$ \\
\hline$W n^{*}$ & $\begin{array}{l}\text { text structure } \\
\text { Performance was worst than } \\
\text { expected }\end{array}$
\end{tabular}

Apabila melihat hasil diatas maka Writing merupakan skill yang paling tidak berhasil. Dari capaian nilai writing dari 61 peserta siswa SD AlAzhar adalah sebagai berikut:

Tabel 5. Capaian nilai writing siswa SD AlAzhar

\begin{tabular}{lr}
\hline Jumlah siswa yang mendapat nilai \\
\hline 6 & $\begin{array}{r}1 \text { peserta } \\
\text { bernama Ahmad Izzudin Alifyandra }\end{array}$ \\
\hline 5 keatas & 3 peserta \\
\hline 4 keatas & 11 peserta \\
\hline 3 keatas & 3 peserta \\
\hline 2 keatas & 16 peserta \\
\hline 2 keatas & 7 peserta \\
\hline 1 keatas & 11 peserta \\
\hline
\end{tabular}

Berikut ini adalah nilai dari ke 4 komponen kemampuan dengan rincian jumlah siswa yang mendapat nilai dari skala 1(terendah) sampai 6 (tertinggi).

$\begin{array}{ccccc} & \text { ENGLISH } & \text { READING } & \text { USAGE } & \text { WRITING } \\ 0 & 0 & 0 & 3 & 11 \\ 1 & 7 & 2 & 15 & 7 \\ 2 & 20 & 7 & 18 & 16 \\ 3 & 26 & 31 & 14 & 3 \\ 4 & 8 & 12 & 9 & 11 \\ 5 & 2 & 4 & 0 & 3 \\ 6 & 1 & 1 & 2 & 1 \\ & 3.1 & 3.6 & 2.8 & 2.5\end{array}$

Jumlah mahasiswa yang terbanyak ada di nilai 2 ( nilai kurang) pada kemahiran usage dan writing, jumlah terbanyak di nilai dua inipun hanya 16 siswa dalam writing dan18 siswa dalam usage dari 61 satu siswa yang berarti kurang dari sepertiga jumlah keseluruhan. yang berarti mayoritas siswa SD Al-Azhar masih lemah kemampuan menulis dan penggunaan bahasa dengan akurat. Sementara kemampuan reading terbesar berada dinilai 3 ( cukup baik) dengan jumlah yang cukup besar yakni 31 siswa aau 50 persen dari total jumlah sisw, berarti kemampuan pemahaman bahasa sudah memadai sehingga nalar siswa dapat terakomodasi dengan baik dalam bahasa Inggris yang dituangkan dalam bentuk jawaban komprehensi terhadap teks bahasa Inggris. 
Dalam writing yang mendapat nilai kosong atau $\mathrm{O}$ ada 11 orang yang berarti bahwa ada 11 siswa yang sama sekali tidak dapat berpartisipasi. Jumlah siswa ini cukup besar dan harus segera dikoreksi. Tetapi disisi lain ada 11 siswa yang mendapat nilai baik (4) dan jumlah ini merupakan jumlah yang cukup menggembirakan.

\section{KESIMPULAN}

Hasil penelitian Evaluasi Cambridge International Primary Program Siswa Al Azhar pada mata pelajaran 'English Language memperlihatkan bahwa mempelajari bahasa asing bagi murid SD tidak diragukan merupakan pembelajaran yang efektif karena setiap anak telah memiliki kemampuan kognitif dalam pembelajaran bahasa. Bahwa setiap bahasa walaupun berbeda memiliki ke universalan bahasa dan faktor ini yang akan mempermudah anak mempelajari bahsa asing sebagai bahasa ke dua dalam hidupnya.

Walau dalam usia dini, para siswa mampu membuktikan kemampuan mereka dan mendapat nilai baik secara keseluruhan namun secara individu apabila dilihat dari komponen reading, usage dan writing mencerminkan perbedaan yang mencolok. Dalam reading para siswa mendapat nilai tertinggi dibandingkan dengan komponen lainnya. Hal ini disebabkan peran logika yang kuat dalam mengambil keputusan disamping peran kemahiran membaca dalam bahasa Inggris.

Komponen Usage masih rendah nilainya dan harus diperbaiki dengan melatih komponen tersebut dalam kelas. Komponen terburuk adalah Writing atau menulis. Hal ini terjadi karena menulis merupakan hasil produktif yang merujuk pada pengerahan kemampuan semua skill kebahasaan. Guru harus lebih banyak melatih anak untuk menulis agar dapat meningkatkan hasil penulisan pada ujian berikutnya.

\section{DAFTAR PUSTAKA}

[1] Departmen Pendidikan Nasional, Panduan Penyelenggarann Program Rintisan SMA Bertaraf Internasional, Jakarta: Direktorat Pembinaan Sekolah Menengah Atas, 2009.

[2] D. Soeyono, Psikolinguistik; Pengantar Pemahaman Bahasa Manusia, Jakarta: Unika Atma Jaya, 2003.

[3] J. Greenberg, (ed.), Universal of language Cambridge, MA: Massachusetts Institute of Technology press, 1963.

[4] D. Soeyono, Echa: Kisah Pemerolehan Bahasa Anak Indonesia, Jakarta: PT Gramedia Widiasarana Indonesia, 2000.

[5] D. Brown, Prinsip Pembelajaran dan Pengajaran Bahasa, Pearson Education.Inc, 2008.

[6] University of Cambridge International Examinations Primary English Curriculum Framework www.cambridge.org, UK: Cambridge, 2006. 